\title{
Acceptance of Mobile Technology in Hedonic Scenarios
}

\author{
Marina Abad \\ Universidad de Deusto, Mundaiz 50 \\ 20012 Donostia, Spain \\ marina.abad@deusto.es
}

\author{
Itxaso Díaz \\ Úbiqa, Alameda Mazarredo 35 \\ 48009 Bilbao, Spain \\ itxaso@ubiqa.com
}

\author{
Markel Vigo \\ CICtourGUNE, Paseo Mikeletegi 56 \\ 20009 Donostia, Spain \\ markelvigo@tourgune.org
}

\begin{abstract}
This paper presents a novel acceptance model for scenarios in which people make use of mobile devices for leisure purposes. The use of mobile devices has such a dominant leisure component that user attitudes towards mobile adoption are strongly determined. Since hedonic aspects play a key role in mobile adoption, they are introduced through the constructs in the proposed Technology Acceptance Model (TAM). To validate the TAM, 79 teenagers took part in an outdoor event that aimed to foster creativity through the use of a mobile phone. Different features of the mobile phone were used by the teenagers to conduct interviews, communicate with peers, and orient themselves using the GPS, among other applications. The proposed TAM yielded successful results since a Principal Components Analysis (PCA) revealed that the constructs Perceived Usefulness, Perceived Ease of Use and Perceived Enjoyment determined Behavioural Intention, exhibiting a high variance of $60.2 \%$. In addition, the explanatory power of the model reached $R^{2}=61 \%$, which is considered strong.
\end{abstract}

Mobile devices, technology acceptance, mobile content generation

\section{INTRODUCTION}

Recent studies show that people make use of mobile devices not only to cover informational needs but also to satisfy geographical demands and for personal information management [4]. Before the advent of third generation ( $3 G$ ) systems, it was commonplace for mobile devices to be used to create bonds between people and to strengthen social networks. Additionally, phones are often utilised to participate in social exchange activities. This use makes the experience special for users because a shared and mutual understanding is evoked [2]. Social activities involving leisure have a predominantly hedonic component and frequently occur outdoors. In most of these situations, people keep their camera phones on hand, as they are powerful tools for multimedia content generation [17]. Understanding how this simultaneously hedonic and mobile context determines technology acceptance will lead to a more profound understanding of the behavioural intentions of users.

Since its inception [6], the Technology Acceptance Model (TAM) has undergone substantial replication, refinement, and extension. Therefore, the TAM has been widely tested and extended. The TAM posits that two cognitive beliefs, Perceived Usefulness (PU) and Perceived Ease of Use (PEOU), are of primary relevance for Behaviour Intention (BI) [6], [12]. Moreover, abundant studies in Psychology and Information Systems have proved that $\mathrm{BI}$ is a strong predictor of actual use behaviour.

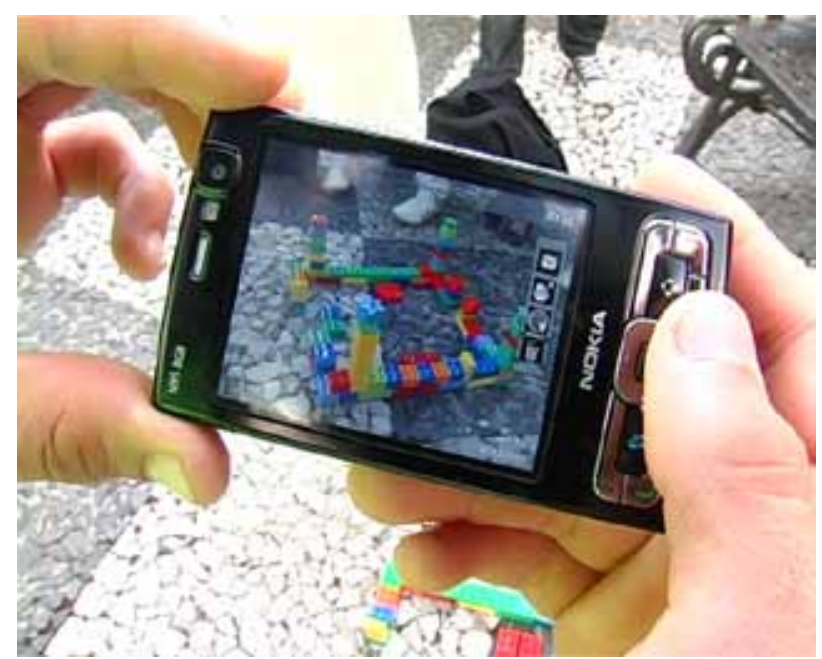

Figure 1: A participant recording one of his creations

Despite the differences in existing models, there is agreement that an individual's belief about using Information Technologies has a significant influence on the user's intended and actual usage behaviour [1].

It is argued that holistic experiences with technology can serve as important explanatory variables in technology acceptance. This argument is rooted in many decades of studies in Psychology, and it is supported by abundant investigations regarding user experiences, such as computer playfulness, enjoyment, flow, intrinsic motivation, and the recent movement to emphasise human affect and emotion in technology design within the fields of Information Systems and Human-Computer Interaction $(\mathrm{HCl})$. Actually, $\mathrm{HCl}$ and TAM are complementary disciplines 
[7]. While the former emphasizes on how to design the interface in such a way that user performance and satisfaction are increased the latter deals with user willingness to use a system based on limited exposure to systems or applications. Foundations of $\mathrm{HCl}$ are drawn from cognitive psychology whereas TAM draws from social and organizational psychology.

In general, PU more strongly determines the acceptance of technologies than does PEOU. Perceived Usefulness refers to an increase in workplace performance that is eminently external to the interaction, and it is regarded as an extrinsic motivation [22]. TAMs have typically been studied in workplace settings, and, therefore, work productivity tends to be cited as one of the strongest motivations for users to adopt a technology. However, there are a number of scenarios in which other motivations such as enjoyment or leisure (in other words, hedonic scenarios) induce the usage of technology. The hedonic nature of a scenario can be defined by the playfulness of the task or by the inherent nature of the environmental setting (e.g., the use of mobile phones). However, the effect of Perceived Enjoyment (when considered in a TAM) has proven to be consistently weaker than the effects of the two previously mentioned beliefs [21].

The latest predictions report ${ }^{1}$ that in 2013, the number of mobile subscribers will reach 5.9 billion. Currently, mobile devices are ubiquitous and used for several purposes, such as personal management, work, and leisure activities. The purpose of the current study is to determine the factors that lead users to adopt mobile technologies in an eminently hedonic and creative setting. From a theoretical point of view, the main contribution of this research is the generalisation of acceptance models to these settings since numerous empirical studies are needed to establish a common ground. While prior research has focused on the utilitarian aspect of technology [12], the present study overcomes this limitation by considering hedonic scenarios. Hence, leisure is regarded as a determinant factor for mobile technology adoption. In addressing this gap on the literature, we focus on an analytical approach to minimise complexity.

The remainder of the article is presented as follows. After an analysis of the state-of-the-art in TAMs and multimedia mobile content generation attitudes, a TAM for hedonic and mobile experiences is proposed in Section 3. In Section 4, the experimental setting where mobile phones were used is described, and in Section 5, the results obtained by a questionnaire about participant experiences are discussed. Finally, conclusions are drawn in Section 6.

\footnotetext{
${ }^{1}$ Available at http://www.itu.int/ITU-D/ict/newslog/ Mo bile + Subscribers + To+Hit+59+Billion+In+2013+ Driven+By+China+India+Africa.aspx
}

\section{RELATED WORK}

This section first covers the technology acceptance model and describes traditional approaches. It then focuses on how people use mobile devices to generate content, particularly with regard to the specific application environment.

\subsection{Technology Acceptance Models}

Traditionally, research on technology acceptance has been focused on workplace settings, thus following a utilitarian aspect of technology. Since mobile devices have an inherent leisure component, the hedonic aspects of mobile interaction should also be considered. The differences between utilitarian and hedonic systems have gradually drawn significant attention from Information Systems researchers. Utilitarian systems aim to provide instrumental value to the user (e.g., instructions to perform a task), while hedonic systems refer to those that provide self-fulfilling values to users (e.g., enjoyment). Existing research on user technology acceptance often emphasises the utilitarian aspect of information systems, while hedonic systems differ in terms of the relative importance of perceptual factors, such as Perceived Usefulness, Perceived Enjoyment (PE), and Perceived Ease of Use in forming Behavioural Intentions. Existing empirical evidence indicates that in hedonic contexts, PE has a stronger impact on $\mathrm{BI}$ [22].

Hedonic information systems aim to provide selffulfilling rather than instrumental value to the user, are strongly connected to home and leisure activities, focus on the enjoyment aspect of information systems use, and encourage long-term rather than productive use. In this sense, playfulness (as defined in terms of concentration, curiosity, and enjoyment) is considered a crucial factor in the pleasure-oriented environments in which enjoyment plays a key role [15]. In utilitarian scenarios, Perceived Usefulness and Perceived Ease of Use are stronger predictors, while in hedonic scenarios, Perceived Playfulness and Perceived Ease of Use are dominant. Note that Perceived Ease of Use is present in both scenarios. This was later empirically confirmed by Van der Heijden [22], who stated that the task, be it utilitarian or hedonic, determines the predictors for technology acceptance. The model he proposed explains $75 \%$ of the variance for BI. Figure 2 shows the squared multiple correlations (bubbles) and standardised regression coefficients (arrows), all of which are significant at $p<.001$. 


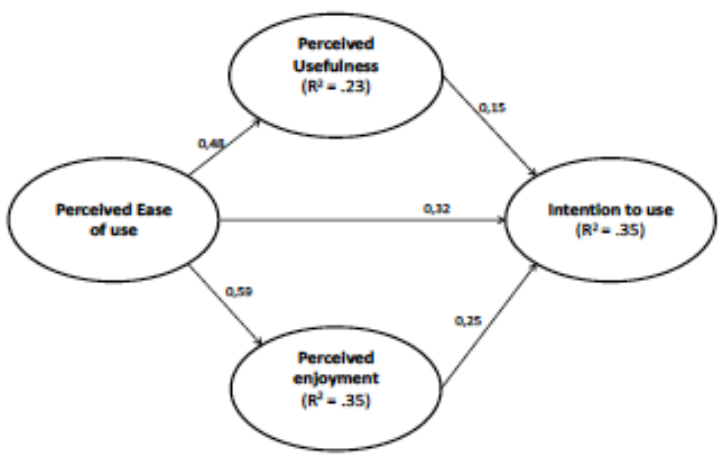

Figure 2: Van der Heijden's acceptance model [22]

Similarly, $Y i$ and Hwang [25] incorporated Playfulness and Learning-goal orientation in their acceptance model (see Figure 3). Both constructs influence Perceived Ease of Use via their effects on application-specific self-efficacy. The model explained substantial variance in Ease of Use (adjusted R2=.51) and moderate variance in Behavioural Intention (adjusted R2 $=.29$ ) and Actual Use (adjusted R2=.14).

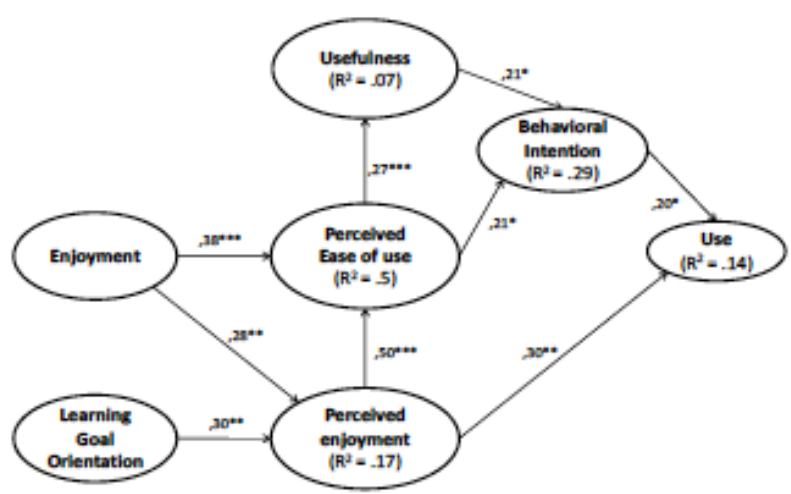

Figure 3: Yi and Hwang's acceptance model [25]

Agarwal and Karahanna [1] introduced the concept of Cognitive Absorption (CA) as the main determinant of the two cognitive beliefs (i.e., PU and PEOU). CA is defined as a state of deep involvement that contains the following five dimensions of cognitive absorption: temporal dissociation, focused immersion, heightened enjoyment, control, and curiosity. They proposed that two individual traits, Personal Innovativeness and Computer Playfulness, are determinants of CA. Cognitive Absorption and Self-Efficacy together explain $46 \%$ of the variance in Perceived Ease of Use, while Cognitive Absorption and Self-Efficacy explain $46.2 \%$ of the variance in Perceived Usefulness. Perceived Usefulness and Perceived Ease of Use account for $48 \%$ of the variance in Behavioural Intention. Recently, Venkatesh and Bala [23] released the socalled TAM3 in which intrinsic motivations such as Computer Playfulness and Perceived Enjoyment are introduced.
The conclusion based on the above-described works is that the hedonic nature of an information system is an important boundary condition to the validity of the technology acceptance model. Specifically, Perceived Usefulness loses its dominant predictive value relative to Ease of Use and Enjoyment. As far as mobile technology acceptance is concerned, Lu et al. [14] found that Individual differences, Social influences, Trust, Technology complexity, Standardisation issues or Network access availability, Perceived short- term and Long-term usefulness, and Ease of use determine willingness to adopt mobile technology. However, this theoretical approach lacks empirical evidence.

\subsection{Mobile Devices as Multimedia Content}

Generators Users have predominantly made use of mobile phones in an independent and a personal manner. Therefore, generated content such as pictures, videos, and texts were unidirectionally transmitted until the advent of mobile social networks, where content circulation is community based. In this context, creativity and sense of belonging have been enhanced [18]. In the case of children aged 10 to 12 , it was observed that when used in a unsupervised social play setting, mobile devices were valued as resources to act locally in a group as well as to create bonds with their peers [9]. Multimedia content was shared as well as the physical device, which was used for creative activities that do not typically include a mobile phone. In terms of broader audiences, it was found that when a phone is extensively used for taking photos, the pictures that evoked an affective experience are widely shared [11]. This finding has also been supported in relation to video content. In that case, users perceived barriers to fully embracing these practices due to technical limitations in storing and sharing video content [16]. Basic values with a strong emotional load such as social recognition, pleasure, happiness, and ambition were found to determine the adoption of mobile multimedia exchange [13].

A novel TAM is herein proposed to capture the constructs that determine behavioural intentions with respect to mobile devices in hedonic scenarios. It is concluded from previous studies that the task (be it utilitarian or hedonic) determines the predictors for acceptance. Yet technology acceptance of mobile devices and hedonic tasks has only been examined separately, not simultaneously, within a study. Therefore, the explanatory power of existing constructs need further exploration for purely hedonic scenarios. In addition, most of the participants in our study were teenagers, who may have specific preferences and attitudes towards mobile technology. Considering these factors, the proposed TAM has a strong affective component. This is confirmed by a study [26] that found perceived 
affective quality has a positive impact on traditional predictors; namely, Ease of use and Usefulness.

\section{A TAM FOR HEDONIC AND MOBILE SETTINGS}

From a literature review, we identified constructs for an acceptance model in hedonic and mobile settings; namely, extrinsic motivations such as Perceived Usefulness (PU) and Perceived Ease of Use (PEOU), and intrinsic motivations such as Satisfaction (SAT) and Perceived Playfulness (PP). Previous research demonstrates that all of these constructs have an impact on Behavioural Intention (BI). Participants completed a questionnaire containing the statements below using a sevenpoint Likert scale ranging from 1 (strongly disagree) to 7 (strongly agree). Results confirm the internal consistency of the proposed constructs.

Note that Perceived Usefulness (Cronbach's alpha=.696) is the construct that measures the perception that a given technology will increase an individual's performance.

PU1. It is useful to fulfil the purpose of the activity.

PU2. We completed all stages without difficulties.

PU3. It made me learn about the activity.

PU4. Tests were useful to complete all stages. PU5. It took a long time to complete the tasks.

PU6. These activities convey a sophisticated view of the town.

PU7. Using these technologies enhances the experience.

PU8. The use of technologies made the activity much better.

Perceived Ease of Use (Cronbach's alpha=.776) measures the participants perception regarding how simple the system was to use.

PEOU1. It was easy to learn.

PEOU2. We felt at ease.

PEOU3. It was easy to use.

PEOU4. Initial instructions were enough to operate the system.
PEOU5. I am skilled user of these kinds of systems.

Satisfaction, (Cronbach's alpha=.768) is conceptually distinct from the attitudes of others in that satisfaction is a transient and experience-specific affect. Generally, it is derived from the positive perception of usefulness, causing an increasing affective reaction to information technologies [3], [5].

SAT1. I am satisfied with this activity.

SAT2. The activity has been agreeable and enriching.

SAT3. It was a creative experience.

SAT4. I like those activities that require the use of technology.

Perceived Playfulness, (Cronbach's alpha=.670). It is closely related to playfulness as defined by Moon and Kim [15]; it is a characteristic of the interaction between an individual and the situation, different from comparatively stable ones over the time. For instance, Playfulness encompasses affective and cognitive episodes that are experienced in the short run, fluctuate over time, and can be influenced by situational factors and the interactions experienced by the user.

PP1. I enjoyed the experience.

PP2. It was fun.

PP3. It was a boring activity.

PP4. I did not realise the time elapsed.

Behavioural Intention measures how likely a user will use a system in the near future. BI1. I would like to participate again in similar activities with other contents.

It is noteworthy to mention that out of these 21 preliminary variables only 14 were selected because subsequent linear regressions we made confirmed that removed variables were not significant. Some variables were removed because Cronbach's alphas showed more consistent constructs: by removing PU5, PEOU3 and PP3 we get .711 for PU, .782 for PEOU and .701 for PP.

Previous research considers both extrinsic and intrinsic motivations to be relevant antecedents for Behavioural Intention. Therefore, we formulate the following hypotheses for mobile scenarios in which hedonic components such as leisure, joy, playfulness, and creativity play a significant role. 
$\mathrm{H} 1$. There is a positive relationship between Perceived Usefulness and Behavioural Intention. H2. There is a positive relationship between Perceived Ease of Use and Behavioral Intention. H3. There is a positive relationship between Perceived Playfulness and Behavioral Intention. H4. There is a positive relationship between Satisfaction and Behavioral Intention.

Additionally, since the model is for application in a leisure context, we also aim to verify that Perceived Playfulness and Satisfaction are significantly stronger predictors of Behavioural Intention than Perceived Usefulness and Perceived Ease of Use.

\section{USING MOBILE DEVICES IN A CREATIVE SETTING}

As a result of a local governmental initiative aimed to foster urban creativity, 79 teenagers (with a mean age of 16 years $(S D=1.4))$ participated in an event in which they had to make use of mobile phones to orient themselves in an urban area and to capture as well as to generate multimedia content. As the event continued, they submitted the content to the organisation so that their progress was checked. Note that the age of users was found to be a moderator of performance expectancy, effort expectancy, and social influence in Technology Acceptance Models [24]. Therefore, the outcomes of this research are applicable within the scope of this age range.

\subsection{Demographics}

Demographic data on participants as well as other relevant information about their attitudes towards information technologies, mobile phones, video gaming, and social networks were gathered. Based on Table 1, most users are knowledgeable about ITs, especially regarding the use of mobile phones.

\begin{tabular}{l|l|r}
\hline & items & $(\%)$ \\
\hline gender & male & 45 \\
& female & $\mathbf{5 5}$ \\
\hline use of mobile phone & never & 3 \\
(hours/week) & less than 3h & 28 \\
& between 3-5h & 11 \\
& more than 5h & $\mathbf{3 7}$ \\
& unknown & 22 \\
\hline use of camera & never & 23 \\
(hours/week) & less than 3h & $\mathbf{4 8}$ \\
& between 3-5h & 5 \\
& more than 5h & 4 \\
& unknown & 20 \\
\hline use of video camera & never & $\mathbf{5 1}$ \\
(hours/week) & less than 3h & 34 \\
& between 3-5h & 0 \\
& more than 5h & 1 \\
& unknown & 1 \\
\hline time spent playing video games & never & 22 \\
(hours/week) & less than 3h & $\mathbf{3 9}$ \\
& between 3-5h & 13 \\
& more than 5h & 15 \\
& unknown & 11 \\
\hline time spent in social networks & never & 3 \\
(hours/week) & less than 3h & 29 \\
& between 3-5h & 24 \\
& more than 5h & $\mathbf{4 2}$ \\
& unknown & 3 \\
\hline
\end{tabular}

Table 1: Demographical and technology usage statistics

\subsection{Procedure}

On November 12th and 13th, 2009, 79 teenagers grouped in 16 teams of 4,5 , and 6 members travelled 16 different routes through the town. Participants passed through a number of stages to complete a route, which took them a mean time of 4 hours. Each stage was understood as a test that should be taken and during which different features of the mobile phone should be used. Each group was given a Nokia N95 mobile phone, with the intent that the groups use most of the phone's features:

- The QR code reader was used to obtain clues to proceed to the next stage.

- The GPS was used jointly with Google Maps for orientation and to proceed to the next stage in the route.

- Interviews were conducted as part of certain tests. The embedded video camera was used to record the interviews.

- Photos were taken to document the entire process. SMSs and MMSs were used to submit the results of each stage (i.e., responses, interviews, and photos). Hence, messaging, Internet access as well as hardware and software features such as the 
video camera, GPS, and the QR codes were used. Since the mobile phone was shared with all members of the groups, it can be implied that users cooperatively used the mobile phones. Once they finished the routes, they completed post-test questionnaires containing the items and constructs of the TAM.

\subsection{Method}

A correlation matrix was computed, and a Principal Components Analysis (PCA) was performed (using statistical SPSS 17 software) to determine the underlying dimensions in our study. The objective of PCA, as a method for data reduction and structure detection, is to group high coefficient items that supposedly belong to the same latent construct. Hence, unobservable and latent factors were extracted from observed and manifest variables. A preliminary analysis to check the adequacy of the model to conduct factor analysis yielded satisfactory results. The Kaiser-Meyer-Olkin test for measuring sampling adequacy was 0.846 , which can be considered an acceptable score. Bartlett's test of sphericity produced $\cdot=456.454$. Both tests provided a minimum standard for conducting Factor Analysis. As a result, it was found the existence of three factors (with eigenvalues $>1.00$ ), accounting for $60.2 \%$ of the total variance. Varimax rotation with Kaiser criteria was used to ascertain which items loaded onto each of the factors. Both tests provide a minimum standard before conducting factor analysis. Finally, an Ordinal Least Squares (OLS) regression is conducted in order to ascertain the relationships between latent factors and $\mathrm{BI}$.

\subsection{Results}

As it can be observed in Table 2 it is noteworthy that the distribution of factors was balanced in terms of percentage of explained variance. This is unlike other acceptance models, in which most of the explained variance is loaded onto the first factor. This demonstrates the strength of the proposed model. Perceived Enjoyment $(21.61 \%)$ and Perceived Usefulness $(21.26 \%)$ had a similar weight, and their cumulative value was $42.87 \%$, which is an acceptable value. The third factor explained the model to a lesser extent (17.33\%) but was also significant. The content of obtained factors showed satisfactory results because of the meaningfulness of the dimensions, with a strong degree of internal consistency. Cronbach's alpha coefficients were 0.809 for the first factor, 0.814 for the second factor, and 0.716 for the third factor, which together are very consistent values. The three factors resulting from the principal components analysis were confirmed by the corresponding scree tests. Of the resulting three scales, two of them, Perceived Usefulness and Perceived Ease of Use practically corresponded with the factors proposed in the theoretical model, and a third factor was redefined as Perceived Enjoyment (PE).

Table 2: Principal Components Analysis results

\begin{tabular}{|c|c|c|c|}
\hline Items/Factors & $\begin{array}{l}\text { Factor 1: } \\
\text { Perceived } \\
\text { Enjoy- } \\
\text { ment }\end{array}$ & $\begin{array}{l}\text { Factor 2: } \\
\text { Perceived } \\
\text { Useful- } \\
\text { ness }\end{array}$ & $\begin{array}{l}\text { Factor 3: } \\
\text { Perceived } \\
\text { ease of } \\
\text { use }\end{array}$ \\
\hline $\begin{array}{l}\text { PP4 } \\
\text { SAT2 } \\
\text { SAT1 } \\
\text { PP1 } \\
\text { PU1 } \\
\text { PU3 } \\
\text { SAT3 } \\
\text { PU6 } \\
\text { PU8 } \\
\text { PU4 } \\
\text { PP2 } \\
\text { PEOU1 } \\
\text { PEOU2 } \\
\text { SAT4 }\end{array}$ & $\begin{array}{l}.841 \\
.722 \\
.661 \\
.668\end{array}$ & $\begin{array}{l}.772 \\
.758 \\
.589 \\
.555 \\
.518 \\
.490 \\
.478\end{array}$ & $\begin{array}{l}.832 \\
.648 \\
.581\end{array}$ \\
\hline Eigenvalue & 5.943 & 1.393 & 1.092 \\
\hline $\begin{array}{l}\% \text { of variance ex- } \\
\text { plained }\end{array}$ & 21.615 & 21.259 & 17.327 \\
\hline $\begin{array}{l}\text { Cumulative } \\
\% \text { of variance } \\
\text { explained }\end{array}$ & 21.615 & 42.874 & 60.201 \\
\hline $\begin{array}{l}\text { alpha (scale relia- } \\
\text { bility) }\end{array}$ & .809 & .814 & .716 \\
\hline $\begin{array}{l}\text { alpha (based } \\
\text { on standarised } \\
\text { items) } \\
\text { scale mean-score }\end{array}$ & $\begin{array}{l}.818 \\
18.18\end{array}$ & $\begin{array}{l}.814 \\
31.54\end{array}$ & .717 \\
\hline
\end{tabular}

PE can be interpreted as "the extent to which the activity of using computers is perceived to be enjoyable in its own right, apart from any performance consequences that may be anticipated" [8] containing variables from Satisfaction and Perceived Playfulness. As a result, $\mathrm{H} 3$ and $\mathrm{H} 4$ were merged into a reformulated $\mathrm{H} 3$ hypothesis as follows.

$\mathrm{H} 3$. There is a positive relationship between Perceived Enjoyment and Behavioural Intention.

To test the relationship between $\mathrm{H} 1, \mathrm{H} 2$, and the reformulated $\mathrm{H} 3$ with respect to $\mathrm{BI}$, a linear regression was conducted. The purpose of this analysis was to determine whether the hypothesised causality was consistent with the data.

Table 3: Results of regression analysis where ${ }^{*} p<.05$, ${ }^{* *} p<.01,{ }^{* * *} p<.001$

\begin{tabular}{l|c|c|c|c}
\hline & $R^{2}$ & $\begin{array}{c}\text { Adjusted } \\
R^{2}\end{array}$ & beta & $\begin{array}{c}\beta \\
\text { (standardized) }\end{array}$ \\
\hline BI=PE+PU+PEOU & .61 & .372 & & \\
Perceived Enjoyment & & & .513 & $.425^{* * *}$ \\
Perceived Usefulness & & & .477 & $.395^{* * *}$ \\
Perceived Ease of Use & & & .224 & $.186^{*}$ \\
\hline
\end{tabular}

As expected, the effects of the three factors were significant. It is remarkable that based on beta differences, the effect of Perceived Enjoyment was the strongest. This finding corroborates the notion that in hedonic contexts, intrinsic motivations are 
stronger predictors of Behavioural Intention than are extrinsic motivations, not only for other hedonic applications such as the WWW [15] but also in a mobile environment. The hypotheses were confirmed because the three factors were directly related to Behavioural Intention:

- H1. There is a positive relationship between Perceived Usefulness and Behavioural Intention $(\beta=.395, p<.001)$.

- H2. There is a positive relationship between Perceived Ease of Use and Behavioural Intention $(\beta=.186, p<.05)$.

- H3. There is a positive relationship between Perceived Enjoyment and Behavioural Intention $(\beta=.425, p<.001)$.

When entering all variables in a single block, we found that the proposed model explains a significant percentage of variance in Behavioural Intention $\left(R^{2}=61 \%\right)$. Moreover, Perceived Enjoyment (PE) and Perceived Usefulness (PU) were more significant than Perceived Ease of Use (PEOU). As expected, the current study provides a view of hedonic scenarios which is contrary to a number of utilitarian models that were developed to explain IT acceptance and posit that two cognitive beliefs, Perceived Usefulness (PU) and Perceived Ease of Use (PEOU), are of utmost importance.

\section{DISCUSSION}

Note, first, that hypotheses had to be reformulated, which may be caused mainly by a lack of agreement on the conceptualisation of not only the constructs or the variables that define them but also on their measurement. Multiple disciplines such as Information Systems, Marketing, Consumer research, and Organisational as well as Social psychology have adopted different approaches to affective design and emotion. As a result, there is no unified view or unified measurement methodology for technology acceptance [18]. Factor analysis led to a reformulation of preliminary H3 (Perceived Playfulness) and $\mathrm{H} 4$ (Satisfaction) into a new $\mathrm{H} 3$, which was defined as Perceived Enjoyment. Another reason to develop this new hypothesis is the conceptual similarities of $\mathrm{H} 3$ and $\mathrm{H} 4$. Moreover, compared to previous studies, the current model explains Behavioural Intention to a greater extent, as evidenced by the higher percentages of explained variance. Additionally, it is remarkable that SAT1 and SAT2, the items describing the experience rather load on Perceived Enjoyment suggesting that enjoyment produced by the activity prevails over the supposedly inherent leisure component of mobile devices (SAT4 loads onto PEOU).

However, it should be taken into account that our results are based on an exploratory rather than confirmatory study. To conduct the latter, a model of structural equations should be run to measure the relationships among constructs. Thus, comparisons with other models are limited. As mentioned, we conducted a Principal Components Analysis and a Ordinal Least Square regression, which allowed for the evaluation of the trade-offs between explained variance and explained parsimony.

The need for a repository of studies to better understand and define constructs for technology acceptance makes our study a remarkable contribution to understanding acceptance with respect to mobile devices in leisure scenarios. From this point of view, we have examined existing TAMs for hedonic scenarios and leisure, and extracted those factors that determine the attitudes that lead to the adoption of technological resources in order to define a model for mobile, hedonic contexts. Therefore, these studies are an invaluable tool for ensuring the quality of technology acceptance and they contribute to an established discipline within Human- Computer Interaction with widely acknowledged techniques and methods.

We corroborate the statement that acceptance models should take into account the specific characteristics of the application environment [24]. In the particular case in which fun, leisure, and joy play a key role, we suggested that affective factors [20] overcome the limitations surrounding the application of TAMs in hedonic scenarios. In this way, additional factors and new variables may explain hedonic acceptance models to a greater extent in leisuredriven activities [1]. Factor analysis confirmed these ideas in a mobile context and allowed us to add the construct of Perceived Enjoyment to the traditional factors of Perceived Usefulness and Perceived Ease of Use. Another relevant outcome is the variance explained through the identified constructs.

As indicated in previous sections of this paper, one of the most commonly reported weaknesses of TAM studies is the low explanatory power of variance [12]. Typically, 30 to $40 \%$ of the variance of the causal relationship is explained, although in some cases only $25 \%$ is explained by independent variables [24] without moderator factors such as those used in the current study. In addition, the vast majority of studies that yielded lower variance explanations did not consider external variables other than original TAM variables. In the present results, the factorial analysis based on the three constructs discussed here shows that the proposed model explained $60.2 \%$ of the variance. All three of the constructs explained an important percentage of variance. Moreover, the positive influences of PU, PEOU, and PE on Behavioural Intention, as suggested by the original 
TAM and other robust models, were confirmed here. The strong significance of Perceived Enjoyment was highlighted by linear regression analysis. This confirms that when affective factors and motivations are introduced, the prediction power of the model is enhanced considerably. Additionally, the value of $\mathrm{R}^{2}$ at $61 \%$ has a greater explanatory power than state-of-the-art approaches, which are only able to achieve a value of approximately $40 \%$ [24]. This may be caused by the fact that mobile devices have an inherent leisure component, regardless of the task. Therefore, the importance of Perceived Enjoyment as an intrinsic motivation factor in an individual's attitude towards using mobile devices in a leisure context has been demonstrated. In this study, the mobile was used for leisure or play. Although ease of use and usefulness are considered important issues in traditional IS environments, the concept of enjoyment plays an important role in increasing behavioural intention.

Nevertheless, we must be careful not to make generalisations. As mentioned already, the interaction context strongly determines the results obtained, and traditional constructs have been adapted. For instance, Perceived Usefulness contains variables such as "It is useful to meet the purpose of the activity" (PU1), "These activities convey a sophisticated view of the town" (PU6), and "It was a creative experience" (PU9), which differ from traditional variables. Even if these variables do not evoke an increase in work productivity or performance in the workplace, it should be noted that the leisure activities participants took in this study are goal oriented. The goal in this case was to reinforce the innovative aspects of the town where the experiment took place. Similarly, other variables that convey added value with respect to the goals set in the experience were included, for example, "It was better than other similar activities" (PU8). Traditional variables such as "The tests were useful to complete the stages" (PU4) aided in obtaining a PU construct that goes a step further than productivity in the workplace.

As far as Perceived Ease of Use is concerned, the literature review suggests that it should have a stronger explanatory power. This was not the case in our study, where PE and PU prevailed over PEOU. The homogeneity of the sample in terms of age and the data in Table 1 leads to the belief that the use of mobile phones is no longer innovative and significant at least for this population in this scenario. Participants stated that they made use of mobile phones five hours a day, and the great percentage of "unknown" responses as compared with the other "unknown" responses suggests that they were skilled users. Likewise, in [19], it is claimed that the age of the potential user has a considerable influence on adopting mobile technology.

Lastly, it is necessary to mention that there remains a need for further research of this type in order to determine the affective factors that play a role in hedonic mobile environments. This is necessary due to the lack of consistency and agreement on this topic. As demonstrated in this study, the meaning of affective variables, or variables that evoke a mixture of affective and cognitive reactions, is not always clear [15].

\section{CONCLUSIONS}

Several models and theories have been developed to explain user technology acceptance behaviour. However, these models have several limitations. The first limitation relates to the explanatory power of the models. Most of the existing studies accounted for less than $60 \%$ of the maximum explained variance, especially those implementing field studies with professional users. Although there may be many other factors that are beyond the scope of specific studies, the differences in explanatory power between laboratory studies and field studies as well as between studies using students and using professionals imply that there are complex contextual factors in the real world that should be taken into account (e.g., the influence of organisational factors such as the willingness of IT usage). The second limitation of these models is the inconsistent relationships identified among constructs, causing researchers to question the generalisability of these models across differing contexts. Additionally, some authors suggest that 0.7 is be a more adequate cutoff for Eigenvalues rather than 1 [10].

It should be taken into account that in the current study, the number of participants, the homogeneity of their ages and the fact that the mobile device was shared introduces subjectivity into the results, making generalisability difficult. Although results are inconclusive, the present study sheds some light on the topic and suggests future research avenues. Future work should utilise confirmatory analysis rather than exploratory analysis, with more users from a broader age range in different hedonic scenarios and using different devices. Nevertheless, the proposed Technology Acceptance Model for hedonic and mobile scenarios is a straightforward tool for understanding the beliefs and attitudes of users with respect to mobile technologies in a leisure scenario.

\section{REFERENCES}

[1] F. Agarwal and E. Karahanna. Time flies when you're having fun: cognitive absorption and beliefs about technology usage. MIS Quarterly,24(4):665-694, 2000.

[2] S. Berg, A. S. Taylor, and R. Harper. Mobile phones for the next generation: device designs 
for teenagers. In $\mathrm{CHI}$ '03: Proceedings of the SIGCHI conference on Human factors in computing systems, pages 433-440, New York, NY, USA, 2003. ACM.

[3] A. Bhattacherjee. Understanding information systems continuance: an expectation-confirmation model. MIS Quarterly,25(3):351-370, 2001.

[4] K. Church and B. Smyth. Understanding the intent behind mobile information needs. In IUI '09: Proceedings of the 13th international conference on Intelligent user interfaces, pages 247-256, New York, NY, USA, 2009. ACM.

[5] D. Compeau and C. Higgins. Application of social cognitive theory to training for computer skills. Information Systems Research,6(2):118-143, 1995. [6] F. Davis. Perceived usefulness, perceived ease of use, and user acceptance of information technology. MIS Quarterly, 13(3):319-340, 1989.

[7] F. Davis. Human Computer Interaction in Management Information Systems: Foundations, chapter 18: On the Relationship Between $\mathrm{HCl}$ and Technology Acceptance Research, pages 395-401. Sharpe, 2005.

[8] F. Davis, R. Bagozzi, and P. Warshaw. Extrinsic and intrinsic motivation to use computers in the workplace. Journal of Applied Social Psychology, 22(14):1111-1132, 1992.

[9] P. Jarkiewicz, M. Frankhammar, and Y. Fernaeus. In the hands of children: exploring the use of mobile phone functionality in casual play settings. In MobileHCl '08: Proceedings of the 10th international conference on Human computer interaction with mobile devices and services, pages 375-378, New York, NY, USA, 2008. ACM.

[10] I. Jolliffe. Discarding variables in a principal component analysis i: Artificial data. Applied Statistics,21:160-173,1972.

[11] T. Kindberg, M. Spasojevic, R. Fleck, and A. Sellen. The ubiquitous camera: An in-depth study of camera phone use. IEEE Pervasive Computing,4:42-50, 2005.

[12] Y. Lee, K. Kozar, and K. Larsen. The technology acceptance model: Past, present and future. Communications of the Association for Information Systems, 12:752-780,2003.

[13] M. Leitner, P. Wolkerstorfer, R. Sefelin, and M. Tscheligi. Mobile multimedia: identifying user values using the means-end theory. In MobileHCl '08: Proceedings of the 10th international conference on Human computer interaction with mobile devices and services, pages 167-175, New York, NY, USA, 2008. ACM.

[14] J. Lu, C. S. Yu, C. Liu, and J. E. Yao. Technology acceptance model for wireless internet. Internet Research,13(3):206-222, 2003. [15] J. W. Moon and Y. G. Kim. Extending the tam for a world-wide-web context. Information Management, 38(4):217-230, 2001.

[16] A. Puikkonen, J. Häkkilä, R. Ballagas, and J.
Mäntyjärvi. Practices in creating videos with mobile phones. In MobileHCl '09: Proceedings of the 11th International Conference on Human-Computer Interaction with Mobile Devices and Services,pages 1-10, New York, NY, USA, 2009. ACM.

[17]E. Reponen, P. Huuskonen, and K. Mihalic. Mobile video recording in context. interactions,13(4):28-30, 2006.

[18] I. Richardson, A. Third, and I. MacColl. Moblogging and belonging: new mobile phone practices and young people's sense of social inclusion. In DIMEA '07: Proceedings of the 2nd international conference on Digital interactive media in entertainment and arts, pages 73-78, New York, NY, USA, 2007. ACM.

[19] S. Sarker and J. D. Wells. Understanding mobile handheld device use and adoption. Communications of the ACM,46(12):35-40,2003.

[20] H. Sun and P. Zhang. Human Computer Interaction in Management Information Systems: Foundations, chapter 14: The role of affect in Information Systems research: A critical survey and a research model, pages 295-329. Sharpe, 2005.

[21] H. Sun and P. Zhang. An empirical study on causal relationships between perceived enjoyment and perceived ease of use. Communications of the Association for Information Systems,7(9):618-645, 2006.

[22] H. van der Heijden. User acceptance of hedonic information systems. MIS Quarterly,28(4):695-704, 2004.

[23] V. Venkatesh and $H$. Bala. Technology acceptance model 3 and a research agenda on interventions. Decision Sciences,39(2):273-315, 2008.

[24] V. Venkatesh, M. G. Morris, G. B. Davis, and F. D. Davis. User acceptance of information technology: Toward a unified view. MIS Quarterly,27(3):425-478, 2003.

[25] M. Y. Yi and Y. Hwang. Predicting the use of webbased information systems: self-efficacy, enjoyment, learning goal orientation, and the technology acceptance model. International Journal of HumanComputer Studies,59(4):431-449, 2003.

[26] P. Zhang and N. Li. The importance of affective quality. Commununications of the ACM, 48(9):105108, 2005. 